\title{
VALUE-AT-RISK (VAR) APPLICATION AT HYPOTHETICAL PORTFOLIOS IN JAKARTA ISLAMIC INDEX
}

\author{
Dewi Tamara ${ }^{1}$ \\ BINUS University International, Jakarta \\ Grigory Ryabtsev ${ }^{2}$ \\ BINUS University International, Jakarta
}

\begin{abstract}
The paper is an exploratory study to apply the method of historical simulation based on the concept of Value at Risk on hypothetical portfolios on Jakarta Islamic Index (JII). Value at Risk is a tool to measure a portfolio's exposure to market risk. We construct four portfolios based on the frequencies of the companies in Jakarta Islamic Index on the period of 1 January 2008 to 2 August 2010. The portfolio A has 12 companies, Portfolio B has 9 companies, portfolio C has 6 companies and portfolio D has 4 companies. We put the initial investment equivalent to USD 100 and use the rate of $1 \mathrm{USD}=\mathrm{Rp} 9500$.

The result of historical simulation applied in the four portfolios shows significant increasing risk on the year 2008 compared to 2009 and 2010. The bigger number of the member in one portfolio also affects the VaR compared to smaller member. The level of confidence $99 \%$ also shows bigger loss compared to 95\%. The historical simulation shows the simplest method to estimate the event of increasing risk in Jakarta Islamic Index during the Global Crisis 2008.
\end{abstract}

Keywords: value at risk, market risk, historical simulation, Jakarta Islamic Index.

\footnotetext{
${ }^{1}$ Faculty of Business, School of Accounting \& Finance - BINUS Business School, dtamara@binus.edu

${ }^{2}$ Alumni of BINUS Business School
} 


\section{INTRODUCTION}

Modern portfolio theory aims to allocate assets by maximising the expected risk premium per unit of risk. In a mean-variance framework, risk is defined in term of the possible variation of expected portfolio returns. The focus on standard deviation as the appropriate measure for risk implies that investors weigh the probability of negative returns equally against positive returns. The choice therefore of mean-variance efficient portfolios is likely to give rise to an inefficient strategy for optimising expected returns for financial assets whilst minimising risk. It would therefore be more desireable to focus on a measure for risk that is able to incorporate any non-normality in the returns distributions of financial assets (Campbell, Huisman and Koedijk, 2001).

In this paper, we develop a portfolio from Jakarta Islamic Index using Value at Risk method. The Value at Risk (VaR) method is one of the widely used approaches for measuring financial risk adopted by commercial as well as noncommercial corporations Hoyt (2007). VAR is an aggregate measure of risk, the largest probable loss a company will have in a certain period with given confidence level for example $99 \%$ or 95\%. Many companies use 98\%, but the risk manager may choose any level with which the company feels most comfortable. With the VaR approach, it is possible to measure the amount of portfolio wealth that can be lost over a given period of time with a certain probability. One of the main advantages of the VAR is that it works across different asset classes such as stocks and bonds. It is also often used as an ex-post measure to evaluate the current exposure to market risk and the decision as to whether exposure should to be reduced (Kooli, 2004).

The Jakarta Islamic Index (JII) was established in 2002 to act as a benchmark in measuring market activities based on Syariah (Islamic law). The Jakarta Islamic Index was created to provide the market with a list of stocks that are in line with the Islamic Sharia investment guidelines. The Index was launched and maintained by the Indonesia Stock Index (IDX). In determining the criteria for the stocks that can be included in the JII, the selection process is supervised by the Sharia Supervisory Board of the Majelis Ulama Indonesia (MUI). The JII was launched on July 3, 2000. The base date of the index is January 1, 1995, with a base value of 100 . 
The index consists of 30 stocks that have passed the selection under the direction of the Sharia Supervisory Board of the Majelis Ulama Indonesia. The reevaluation process of the listed shares is held every six months, in January and in July in the same year.

Islamic law prohibits a company from involving itself in activities related to gambling, speculation, and traditional banking and financing. The JII lists equities that produce or distribute food, drink, or morally harmful items that stand in contradiction with Islamic values. The prohibited business sectors are businesses that include the following activities of gambling and any other games that are categorized as gambling. Second is the conventional financial institutions, including: conventional banking institutions and insurances. Third are the activities that include the productions, distributions and tradings of foods and beverages that are prohibited by Islamic sharia. Fourth, are the activities that include the productions, distributions and provisions of services that are deemed as unlawful by Islamic sharia. Fifth is the share must be listed on the exchange for at least three months prior to application. Sixth is the company's annual or mid-year financial report must have an Obligation Asset ratio of no more than $90 \%$. Sevent is the rank in the top 60 shares based on the previous year's average Market Capitalization. Eighth is the rank in the top 30 shares based on the previous year's average liquidity in the regular market.

Hondoko (2009) or Sanjaya (2008) conduct research to analyze Indonesian Stock indexes. However, these studies do not analyze the portfolio based on JII shares. The thirty companies included in JII plays significant role in country economics, so it is important to calculate and measure the risk using Value-at-Risk method.

The outline of the remaining sections will be as follows. In Section 2, the financial risk review is given. Section 3 in the theoritical framework of $\mathrm{VaR}$. Section 4 shows data and methodology. Section 5 will discuss the finding and section 6 concludes. 


\section{FINANCIAL RISK}

Goorbergh and Vlaar (1999) summarize the three types of risk are distinguished, business risk, strategic risk and financial risk. Business risk pertains to the risk firms face solely on account of their presence in some product market. This type of risk stems from uncertainty in such activities as technological innovations, product design and marketing. Strategic risk results from fundamental changes in the economic or political environment. A case in point is the expropriation of land and the nationalisation of businesses in communist countries in this century. This type of risk is typically very hard to quantify. And finally, there's financial risk, which is caused by movements in financial markets. For instance, changes in the prices of financial assets may affect the investment portfolio of a financial institution and bring about huge losses or gains. Although all three kinds of risk are important, we shall solely be concerned with financial risk for the remainder of the analysis.

Financial risk can be broken down further into various categories. There's market risk brought on by changes in the prices of financial assets and liabilities, credit risk caused by the unwillingness or inability of counterparties to fulfill their contractual obligations, liquidity risk resulting from insuficient market activity, operational risk due to inadequate systems, management failures or fraud, and legal risk that arises when a counterparty does not have the authority to engage in a transaction. Risk in generally, can be defined as the volatility of unexpected outcomes. Financial risks can be defined as those which relate to possible losses in financial markets, such as losses due to interest rate movements or defaults on financial obligations.

An extensive literature exists on the analysis of market risk. The availability of information from financial markets allows us to empirically examine this type of risk better than any other kind. In order to examine market risk, it has to be measured. There are different ways to do this. One commonly used measure of the price risk of an investment in some financial asset, is the standard deviation of the price of that asset. But if one is particularly interested in the maximum down-side risk one is exposed to, the so-called Value-at-Risk, VaR for short, might be a more suitable instrument. It was made popular by US investment bank J.P. 
Morgan, who incorporated it in their risk management model RiskMetricsTM, to which we will come back later.

Loosely speaking, the Value-at-Risk of a portfolio is the maximum loss that may be su_ered on that portfolio in the course of some holding period, during which the composition of the portfolio remains unchanged. The length of this holding period is short-term, usually one day to a few weeks. So the Value-at-Risk of an investor's portfolio is the maximum amount of money he or she may lose in a short period of time. Value at Risk was initially developed to deal with one aspect of financial risk, market risk. Market risk arises from movements in the level of market prices. Market risk can take two forms: absolute risk, measured in money terms (i.e. Rupiah, dollars), and relative risk, measured relative to a benchmark index (Jorion, 2002).

\section{THEORITICAL FRAMEWORK OF VALUE-AT-RISK}

Value-at-Risk (VaR) is a widely used risk measure of the risk of loss on a specific portfolio of financial assets. For a given portfolio, probability and time horizon, VaR is defined as a threshold value such that the probability that the mark-to market loss on the portfolio over the given time horizon exceeds this value (assuming normal markets and no trading in the portfolio) is the given probability level.

In the simple words - VaR summarizes the worst loss over a target horizon with a given level of confidence. More formally, VaR describes the quantile of the projected distribution of gains and losses over the target horizon. The original purpose of $\mathrm{VaR}$ was to quantify market risk. By now, the industry has converged on a set of risk measures that work well. In contrast with traditional risk measures, VaR provides an aggregate view of a portfolio's risk that account for leverage, correlations and current position. As a result, it is a truly a forward-looking risk measure. 


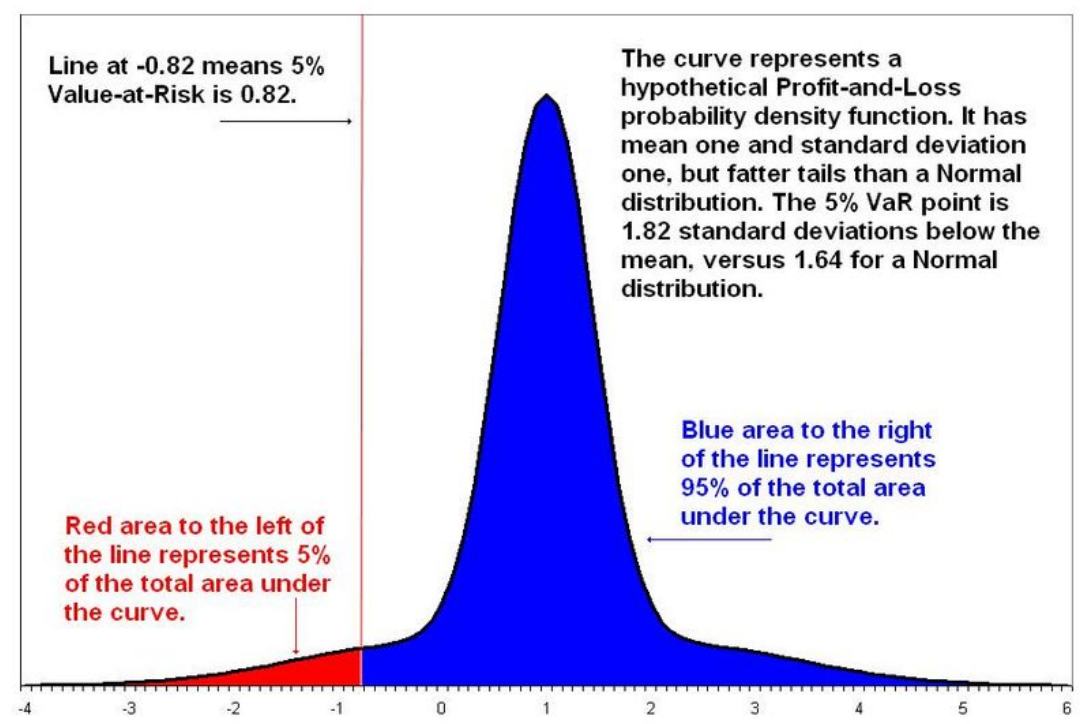

Source: http://www.investopedia.com/articles/04/092904.asp

Figure 1: Diagram VaR.

While the term "Value at Risk" was not widely used prior to the mid 1990s, the origins of the measure lay further back in time. The mathematics that underlies VaR was largely developed in the context of portfolio theory by Harry Markowitz and others, though their efforts were directed towards a different end - devising optimal portfolios for equity investors. In particular, the focus on market risks and the effects of the comovements in these risks are central to how VaR is computed. The first regulatory measures that evoke Value at Risk, though, were initiated in 1980, when the SEC tied the capital requirements of financial service firms to the losses that would be incurred, with 95\% confidence over a thirty-day interval, in different security classes; historical returns were used to compute these potential losses. Although the measures were described as haircuts and not as Value or Capital at Risk, it was clear the SEC was requiring financial service firms to embark on the process of estimating one month 95\% VaRs and hold enough capital to cover the potential losses. In 1995, J.P. Morgan provided public access to data on the variances of and co-variances across various security and asset classes, that it had used internally for almost a decade to manage risk, and allowed 
software makers to develop software to measure risk. It titled the service "RiskMetrics" and used the term Value at Risk to describe the risk measure that emerged from the data. The measure found a ready audience with commercial and investment banks, and the regulatory authorities overseeing them, who warmed to its intuitive appeal. In the last decade, $\mathrm{VaR}$ has becomes the established measure of risk exposure in financial service firms and has even begun to find acceptance in non-financial service firms.

Despite VaR's popularity, there are some major problems with using it as the risk measure in portfolio optimization. First, VaR is not a coherent risk measure - it lacks subadditivity based on the research of Artzner et al. (1997). Thus, the VaR of a portfolio of two funds may end up greater than the sum of the VaRs of the individual funds. Second, according Rockafellar (2000) to even though the purpose of VaR is to reduce extreme losses, minimization of VaR can lead to an undesirable stretch of the tail of the distribution exceeding VaR. Third, Natarajan (2008) said that VaR optimization is a stochastic programming problem of a special kind (namely, one with probability constraints), and as such, it is inherently difficult to solve. Indeed, while a substantial part of the VaR estimation literature deals with the problem of computing the VaR given a particular asset allocation, the literature on actual optimization of portfolio $\mathrm{VaR}$ is relatively scarce. Last, but not least, the standard VaR measure presumes that asset returns are normally distributed, while it is widely documented that they really exhibit non-zero skewness and excess kurtosis and, hence, the VaR measure either underestimates or overestimates "true risk" (Angelidis, 2008).

Higher confidence level makes greater VaR measure. Varying the confidence level provides useful information about the return distribution and potential losses. Based on previous research average confidence level vary from $95 \%$ to $99 \%$.

Sanjaya (2008) assumes that long time horizon makes greater VaR measure. The choice of the horizon depends on the use of VaR. If the purpose is to provide an accurate benchmark measure of downside risk, the horizon should be relatively short, ideally less than the average period for major portfolio rebalancing.

Tamara, D. \& Ryabtsev, G. / Journal of Applied Finance and Accounting 3(2) 153-180 
In contrast, if the VaR number is being used to decide how much capital to set aside to avoid bankruptcy, then a long horizon is advisable. Institutions will want to have enough time for corrective action as problems start to develop.

The methods to calculate Value-at-Risk consist of three approach, first historical simulation, variance-covariance and Monte Carlo. According to Linsmeier (2000), historical simulation requires relatively few assumptions about the statistical distributions of the underlying market factors. The main benefit is that it can cope with all portfolios that are either linear or non-linear. The method does not assume any specific form of the distribution of price change/return. The method captures the characteristics of the price change distribution of the portfolio, as $\mathrm{VaR}$ is estimated on the basis of actual distribution. Based on the same work of Linsmeier (2000), this is very important, as the Historical Simulation method would be on the basis of available past data. If the past data does not contain highly volatile periods, then Historical Simulation method would not be able to capture the same. Hence, Historical Simulation should be applied when we have very large data points that are sufficiently large to take into account all possible cyclical events. While Sanjaya (2008) wrote that Historical Simulation method takes a portfolio at a point of time and then revalues the same using the historical price series.

The variance - covariance approach is based on the assumption that the underlying market factors have a multivariate normal distribution. Using this assumption (and the approximation involved in mapping the portfolio that is detailed later), one can determine the distribution of mark-to-market portfolio profits and losses, which is also assumed to be normal. Once the distribution of possible portfolio profits and losses has been obtained, standard mathematical properties of the normal distribution are used to determine the loss that will be equaled or exceeded $x$ percent of the time (i.e., the VaR) (Linsmeier, 2000). The variance - covariance approach is particularly easy to implement because it involves a simple matrix calculations.

Monte Carlo simulations cover a wide range of possible values in financial variables and fully account for correlations. There are two steps in that method. Starting with specifying a stochastic process for financial 
variables as well as process parameters. Process parameters can be risk and correlation received from historical data. The second step is to path fictitious price and simulated for all variables.At each horizon considered, the portfolio is marked to marked using full valuation as in the historical simulation method. Monte Carlo method is similar to historical simulation method, except that the hypothetical changes in prices for assets are created by random draws from a prespecified stochastic process instead of sampled from historical data (Jorion, 2002).

According to Jorion (2002) Monte Carlo is the most powerful method to compute VAR. It can account for a wide range of exposures and risks, including nonlinear risk, volatility risk and other risks. It is flexible enough to incorporate time variation in volatility, fat tails and extreme scenarios. Monte Carlo method also can incorporate the passage of time, which will create structural changes in portfolio. This includes the time decay of options or effect of prespecified trading or hedging strategies. Even this method is quite good it still has several weaknesses. This method is the most expensive to implement in terms of system infrastructure and intellectual development. The method is relatively onerous to develop from scratch. Another potential weakness of the method is model risk. Monte Carlo relies on specific stochastic processes for the underlying risk factors as well as pricing models for securities such as options or mortgages. One more weakness is that the method is subjected to sampling variation which is due to the limited number of replications. Overall, this method is the most comprehensive approach to measuring market risk according to Jorion (2002). That is why in this reaserch athor will not use this method for calculating VAR.

Based on importance of VAR for financial measurements there are many researches were conducted in recent time. One of them written by Jorion (2002) discuss the problem of how informative are the VAR disclosures. Author tested the informativeness of VAR measures by estimating the relation between the VaR based quarterly volatility and the absolute value of the unexpected trading revenue in the subsequent quarter. The result provided by Jorion is that the individual bank-specific regressions reveal some evidence that forecast of volatility in unexpected trading revenues derived from VAR disclosure are positively associated with magnitude of the next quarter's unexpected trading revenues. Another work provided by Chien-Liang Chiu in 2005 employs three Value-at-Risk models (GARJI, 
ARJI and asymmetric GARCH) to compare the performance of 1-dayahead VaR estimates. The influences of price jumps and asymmetric information on the performance of $\mathrm{VaR}$ were investigated. The results suggest for asset returns which exhibit time-variant jumps and information asymmetry, the VaR estimates generated by the GARJI and ARJI models provide reliable accuracy for low and high confidence levels. Moreover, as MRSB indicated, the GARJI model is more efficient than alternative models. The common problems of measurements were described by Cakici (2004). In his work: "Value at Risk and Expected Stock Returns". Author used a time series approach to test the empirical performance of $\mathrm{VaR}$ at the portfolio level. The results, based on book-to-market portfolios, indicate that $\mathrm{VaR}$ has additional explanatory power after the characteristics of market return; size, book-to-market ratio, and liquidity are controlled for.

\section{DATA AND METHODOLOGY}

\section{Data}

We take the companies that were included at least two times into JII list from 1 January 2008 until 31 May 2010. Based on the reevaluation held in January and July, we divide into five periods : January 2008 - June 2008, July 2008 - December 2008, January 2009 - June 2009, July 2009 December 2009, January 2010 - June 2010 in which each periods consist of 30 companies. In this case, the total number companies listed at JII from January 2008 until May 2010 is 54. The details of companies listed in Period I to $\mathrm{V}$ are in Table 1.

Table 1. The Companies Listed in Period I-V, January 2008-June 2010.

\begin{tabular}{|c|c|c|c|c|c|c|c|c|c|}
\hline No & PERIOD I & & PERIOD II & & $\begin{array}{c}\text { PERIOD } \\
\text { III }\end{array}$ & & $\begin{array}{c}\text { PERIOD } \\
\text { IV }\end{array}$ & & PERIOD V \\
\hline & $\begin{array}{l}\text { JAN- } \\
\text { 08/JUN08 }\end{array}$ & & $\begin{array}{l}\text { JUN- } \\
\text { 08/DEC-08 }\end{array}$ & & $\begin{array}{l}\text { DEC- } \\
\text { 08/MAY09 }\end{array}$ & & $\begin{array}{l}\text { JUN- } \\
09 / N O V-09\end{array}$ & & $\begin{array}{l}\text { DEC- } \\
\text { 09/MAY-10 }\end{array}$ \\
\hline 1 & AALI & & AALI & & AALI & & AALI & & AALI \\
\hline 2 & ANTM & & ANTM & & ACES & * & $A D R O$ & $*$ & $A D R O$ \\
\hline 3 & $A P E X$ & & ASRI & * & ANTM & & ANTM & & ANTM \\
\hline 4 & BMTR & * & BISI & & $A P E X$ & * & ASII & & ASII \\
\hline 5 & $B N B R$ & & $B K S L$ & & ASII & * & BISI & & BISI \\
\hline
\end{tabular}




\begin{tabular}{|c|c|c|c|c|c|c|c|c|c|}
\hline No & PERIOD I & & PERIOD II & & $\begin{array}{c}\text { PERIOD } \\
\text { III }\end{array}$ & & $\begin{array}{c}\text { PERIOD } \\
\text { IV }\end{array}$ & & PERIOD V \\
\hline 6 & BTEL & & BMTR & & BISI & & BMTR & & BMTR \\
\hline 7 & BUMI & & BUMI & & BMTR & & BTEL & $*$ & BRPT \\
\hline 8 & $C M N P$ & $*$ & CTRA & & BRPT & $*$ & BUMI & & $B S D E$ \\
\hline 9 & CTRA & & CTRO & $*$ & BUMI & & CTRA & $*$ & BTEL \\
\hline 10 & ELTY & $*$ & ELSA & $*$ & CTRP & & DEWA & $*$ & BUMI \\
\hline 11 & FREN & & ELTY & & ELSA & & ELSA & & CTRA \\
\hline 12 & HITS & $*$ & INCO & & IIKP & $*$ & ELTY & $*$ & DEWA \\
\hline 13 & INCO & & INTP & & INCO & & HEXA & $*$ & ELSA \\
\hline 14 & INTP & & ITMG & $*$ & INDY & * & INCO & & INCO \\
\hline 15 & $J R P T$ & $*$ & KIJA & & INTP & & INDY & & INDY \\
\hline 16 & KIJA & $*$ & KLBF & $*$ & ITMG & & INTP & & INTP \\
\hline 17 & KLBF & & LPKR & $*$ & KLBF & & ITMG & & ITMG \\
\hline 18 & MPPA & * & LSIP & & LSIP & & KIJA & $*$ & KLBF \\
\hline 19 & PLIN & $*$ & MNCM & & MIRA & $*$ & KLBF & & LPKR \\
\hline 20 & PTBA & & PTBA & & MNCM & & LPKR & $*$ & LSIP \\
\hline 21 & $R A L S$ & $*$ & SGRO & $*$ & MPPA & $*$ & LSIP & & PTBA \\
\hline 22 & SMAR & & SMGR & & PTBA & & PTBA & & SGRO \\
\hline 23 & SMGR & & TINS & & SGRO & & SGRO & & SMGR \\
\hline 24 & SMRA & $*$ & TLKM & & SMGR & & SMGR & & TINS \\
\hline 25 & TINS & & TOTL & $*$ & TBLA & $*$ & TINS & & TLKM \\
\hline 26 & TLKM & & TRUB & & TINS & & TLKM & & TRUB \\
\hline 27 & TRUB & & UNSP & $*$ & TLKM & & UNSP & & UNSP \\
\hline 28 & TSPC & $*$ & UNTR & & UNSP & & UNTR & $*$ & UNTR \\
\hline 29 & UNTR & & UNVR & & UNVR & & UNVR & & UNVR \\
\hline \multirow[t]{2}{*}{30} & UNVR & & WIKA & $*$ & WIKA & & WIKA & & WIKA \\
\hline & * - New & & & & & & & & \\
\hline
\end{tabular}

Source: Jakarta Islamic Index, 2010

From the 54 companies, 12 companies were listed 5 times, which we categorize in portfolio A. Nine companies were listed 4 times we categorize as Portfolio B. Six companies that were listed three times we 
pool in Portfolio C. The last five companies that were listed two times will be Portfolio D. Table 2 shows the details of the sample representation.

Table 2. Four Portfolios from Jakarta Islamic Index used in VAR

\begin{tabular}{|c|c|c|c|c|c|}
\hline \# & Code & Company Name & $\begin{array}{l}\text { Times } \\
\text { in } \\
\text { index }\end{array}$ & $\begin{array}{c}\text { Total } \\
\text { Companies }\end{array}$ & \\
\hline 1 & AALI & Astra Agro Lestari Tbk & 5 & \multirow{12}{*}{12} & \multirow{12}{*}{ Portfolio A } \\
\hline 2 & ANTM & Aneka Tambang (Persero) Tbk & 5 & & \\
\hline 3 & BMTR & Global Mediacom Tbk & 5 & & \\
\hline 4 & INCO & International Nickel Indonesia & 5 & & \\
\hline 5 & INTP & Indocement Tunggal Prakasa Tbk & 5 & & \\
\hline 6 & KLBF & Kalbe Farma Tbk & 5 & & \\
\hline 7 & PTBA & Tambang Batubara Bukit AsamTbk & 5 & & \\
\hline 8 & SMGR & Semen Gresik (Persero) Tbk & 5 & & \\
\hline 9 & TINS & Timah (Persero) Tbk & 5 & & \\
\hline 10 & TLKM & Telekomunikasi Indonesia Tbk & 5 & & \\
\hline 11 & UNVR & Unilever Indonesia Tbk & 5 & & \\
\hline 12 & BUMI & Bumi Resources Tbk & 5 & & \\
\hline 13 & CTRA & Ciputra Development Tbk & 4 & \multirow{9}{*}{9} & \multirow{9}{*}{ Portfolio B } \\
\hline 14 & UNTR & United Tractors Tbk & 4 & & \\
\hline 15 & ELSA & Elnusa Tbk & 4 & & \\
\hline 16 & ITMG & Indo Tambangraya Megah Tbk & 4 & & \\
\hline 17 & LSIP & PP London Sumatra Indonesia Tbk & 4 & & \\
\hline 18 & SGRO & Sampoerna Agro Tbk & 4 & & \\
\hline 19 & UNSP & Bakrie Sumatra Plantations Tbk & 4 & & \\
\hline 20 & WIKA & Wijaya Karya (Persero) Tbk & 4 & & \\
\hline 21 & BISI & BISI International Tbk & 4 & & \\
\hline 22 & LPKR & Lippo Karawaci Tbk & 3 & \multirow{5}{*}{6} & \multirow{5}{*}{ Portfolio C } \\
\hline 23 & ELTY & Bakrieland Development Tbk & 3 & & \\
\hline 24 & ASII & Astra International Tbk & 3 & & \\
\hline 25 & BTEL & Bakrie Telecom Tbk & 3 & & \\
\hline 26 & KIJA & Kawasan Industri Jababeka Tbk & 3 & & \\
\hline
\end{tabular}




\begin{tabular}{|c|c|c|c|c|c|}
\hline \# & Code & Company Name & $\begin{array}{l}\text { Times } \\
\text { in } \\
\text { index }\end{array}$ & $\begin{array}{c}\text { Total } \\
\text { Companies }\end{array}$ & \\
\hline 27 & TRUB & Truba Alam Manunggal E. Tbk & 3 & & \\
\hline 28 & BRPT & Barito Pacific Tbk & 2 & \multirow{5}{*}{5} & \multirow{5}{*}{ Portfolio D } \\
\hline 29 & INDY & Indika Energy Tbk & 2 & & \\
\hline 30 & DEWA & Darma Henwa Tbk & 2 & & \\
\hline 31 & MPPA & Matahari Putra Prima Tbk & 2 & & \\
\hline 32 & ADRO & Adaro Energy Tbk & 2 & & \\
\hline
\end{tabular}

Source: conducted by author

\section{Methodology}

Now we have 4 different hypothetical portfolios in Jakarta Islamic Index, with sample period from 2 January 2008 to 1 January 2010 (500 data points). Wwe will calculate VaR value for Portfolio A, B, C, and D using Historical Simulation (HS).

The underlying assumption of historical simulation method is that the near future of return distribution of Jakarta Islamic Index will be follow the recent past return distribution. Therefore, the historical data can be used to estimate the market risk profile of Jakarta Islamic Index.

This method needs three major consideration. First is the confidence level. The Basel Committe requires 99\% confidence level in official reporting (Basel Commitee, 2006), but a lower level of confidence (e.g 95\%) can be used for internal reporting ( Bhattacharya, 2007). In this study, we use either $95 \%$ and $99 \%$ for comparison reason.

Second is the Forecast horizon. The length of the period, for which the expected maximum loss is forecasted, is known as forecast horizon or holding period. The portfolio composition is assumed to remain static for VaR over the holding period. In practice, the holding period can vary form one trading day to some years, but the Basel Committe requires the use of 10-day holding period for official reporting. In this study we use 10-days holding period as well (Dutta et al., 2007).

Third is the historical observation period. The length of the data sample in VaR calculation is known as the historical observation period. This 
observation period connects VAR to the history of the market risk factors, as the volaitlity of the risk factors is determined based on the length of the historical observation period. The regularoty sets a minimum length of one year for the historical observation period (Basel Committe, 2005), while the period may vary from a month to several years in practice. A oneperiod VAR can be scaled to a long horizon VAR by multiplying by the length of the horizon. For example, a one-day $\mathrm{VaR}$ may be scaled to tenday VaR by multiplying it with 10 .

The value-at-risk of a portfolio summarizes the expected maximum loss (or worst loss) over a target horizon within a given confidence interval. The following steps are required to compute VAR :

\section{Mark-to- market of the current portfolio}

We calculate the profit and loss from the Jakarta Islamic Index return, which replicate the portfolio. The positive and negative return are generated by an asset (or portfolio) over the period t, P/Lt. For statistical purposes, therefore, it is convenient to define the return in logarithmic terms as $\mathrm{r}_{\mathrm{t}}=\ln \left(\mathrm{I}_{t} / \mathrm{I}_{\mathrm{t}-1}\right)$ where $\mathrm{I}_{\mathrm{t}}$ is the index at time $\mathrm{t}$. The logarithmic return can also be rewritten as $\mathrm{rt}_{\mathrm{t}}=\ln \left(1+\mathrm{R}_{\mathrm{t}}\right)$ where $\mathrm{R}_{\mathrm{t}}$ is the percentage return showing. Thus after the entire analysis is done in terms of logarithmic return, the results can be restated in terms of percentage returns :

$$
\boldsymbol{R}_{p, K}=\sum_{t=1}^{N} \mathrm{w}_{l, t} \boldsymbol{R}_{l, k}
$$

Where the positive value indicates profit, the negative value indicates loss.

\section{Measure the variability of the risk factors}

We calculate a distributional fitting of profit and loss is developed to capture the nature of the distribution, as the distributional assumption is one of the key points for VAR computation. The measurement of the variability of the risk factors using following formula :

$$
\operatorname{VaR}(\text { mean })=\mathbf{E}(\mathbf{W})-W^{*}=-W_{0}\left(R^{*}-k\right),
$$


Where the portfolio at the end of target horizon is $\mathrm{W}=\mathrm{W}_{\mathrm{v}}\left(\mathbb{1}+\mathrm{E}^{2}\right)$; expected return of $\mathrm{R}$ is $\mu$ and volatility is $\sigma . W^{n}$ is the lowest portfolio value at the given confidence level.

3. Set the time horizon or the holding period. The holding period is one day.

4. Set the confidence level. The confidence level is at $95 \%$ and $99 \%$.

5. Report the worst loss by processing all the preceding information.

In this historical simulation, we put an amount of equivalent USD 100 for each portfolio, and calculate the VaR for $95 \%$ and $99 \%$ through the whole sample from 1 January 2008 to 2 August 2010 (900 trading days).

\section{FINDINGS AND DISCUSSIONS}

\section{Descriptive Statistic}

In this section we will explain about the descriptive statistic on Jakarta Islamic Index in the sample periods of 2008-2010.

Table 3. Descriptive statistic of JII 2008-2010

\begin{tabular}{|l|r|c|c|}
\hline \multicolumn{1}{|c|}{ Remark } & $\mathbf{2 0 0 8}$ & $\mathbf{2 0 0 9}$ & $\mathbf{2 0 1 0}$ \\
\hline Average return & -0.00304159 & 0.00289580 & 0.00110445 \\
\hline Median & -0.00130545 & 0.00154845 & 0.00119641 \\
\hline Std deviation & 0.02893521 & 0.01824117 & 0.01456010 \\
\hline Max & 0.09528293 & 0.08177992 & 0.09149159 \\
\hline & & - & - \\
Min & -0.12940396 & 0.04603636 & 0.04212328 \\
\hline Kurtosis & 2.49447294 & 1.76495534 & 6.25320843 \\
\hline Skewness & -0.26826194 & 0.43768037 & 0.82425309 \\
\hline Normdist & 0.54185856 & 0.43693255 & 0.46976732 \\
\hline
\end{tabular}

The descriptive statistic on Jakarta Islamic Index has average of return of $0,3 \%, 0,2 \%$ and $0,01 \%$ on $2008,2009,2010$ respectively. It shows the skewness and kurtosis compared to its normal distribution. Its maximum reaches $0,9 \%$ and the minimum is $0.04 \%$. 


\section{Portfolio A}

The result of the historical simulation from Portfolio A is as follows :

$\begin{array}{lll} & \text { IDR } 11,400,000 \\ \text { VaR 95\% } & \text { Rp -475,003.24 } & \text { 1 Jan 2008-2 Aug 2010 } \\ \text { VaR 99\% } & \text { Rp -837,635.85 } & \text { 1 Jan 2008-2 Aug 2010 }\end{array}$

The maximum loss of Portfolio A with the initial investment of $\mathrm{Rp}$ 11,400.000 will be Rp 475.000 and Rp 837.635 with level of confidence 95\% and 99\% respectively.

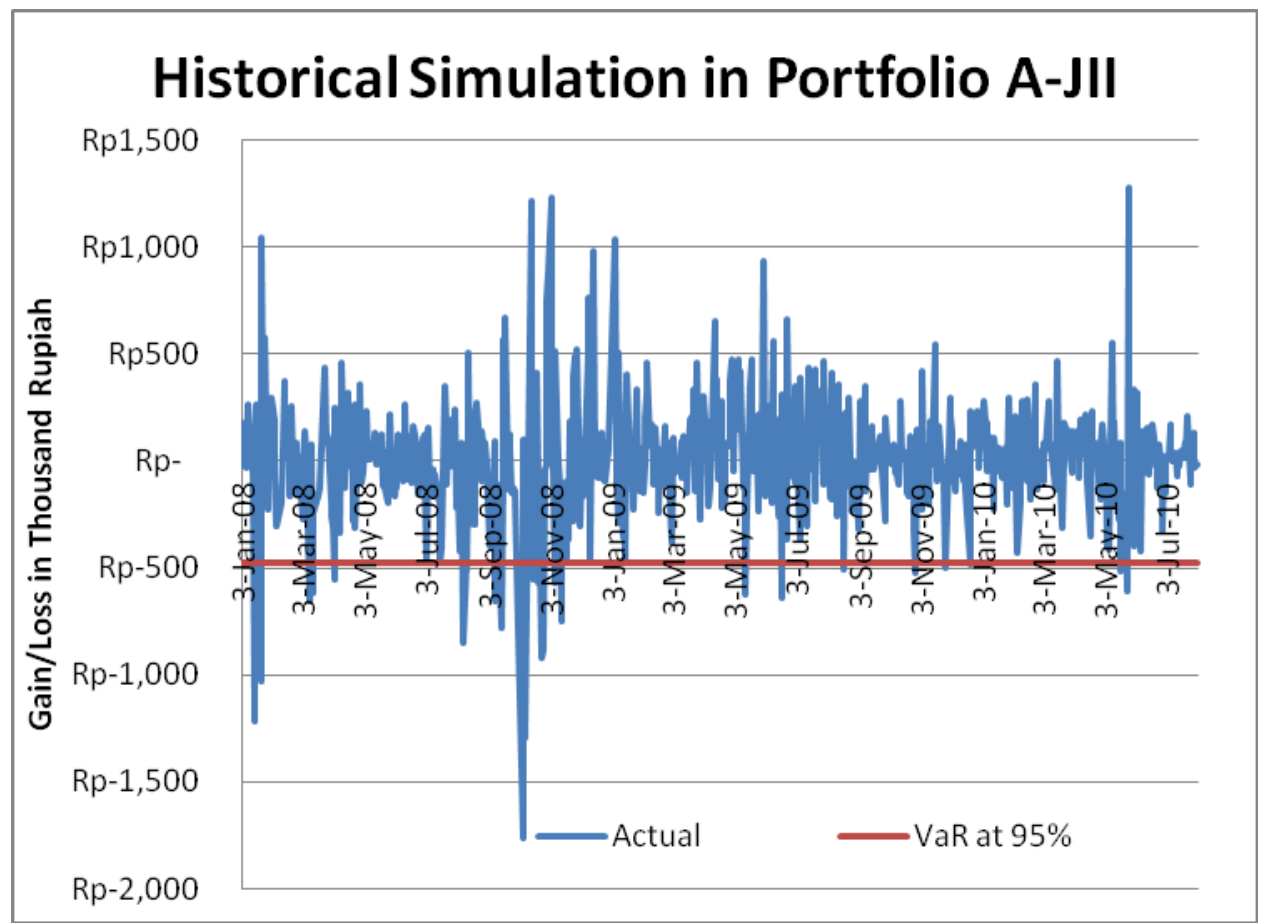

Figure 2. Historical Value-at-Risk (95\% confidence level) for Portfolio A from 1 Jan 2008 to 2 Aug 2010 
Figure 2 shows the result of historical simulation in Portfolio A-JII on actual daily gains and losses using $\mathrm{VaR}$ at $95 \%$. The flat red line was daily maximum loss estimation from historical VaR. The 95\% confidence level VaR was calculated as the fifth percentile of the Portfolio A for the period of 1 January 2008 to 2 August 2010.

The confidence level of $95 \%$ indicates that for 95 out of 100 trading days, the amount in Portfolio A will increase or decrease, but the decrease will be not more than Rp 475,000. The maximum actual loss is Rp 628,673 in the month of October 2008.

Using historical simulation $\mathrm{VaR} 95 \%$, there are 45 days out of 900 trading days that the actual losses will exceed Rp 475,000. In these typical days, the investor should follow closely the bad or negative news because the nature of Jakarta Islamic Index will follow the movement of IHSG. They can prevent the losses by selling the portfolio A if the loss approaches Rp 475,000 .

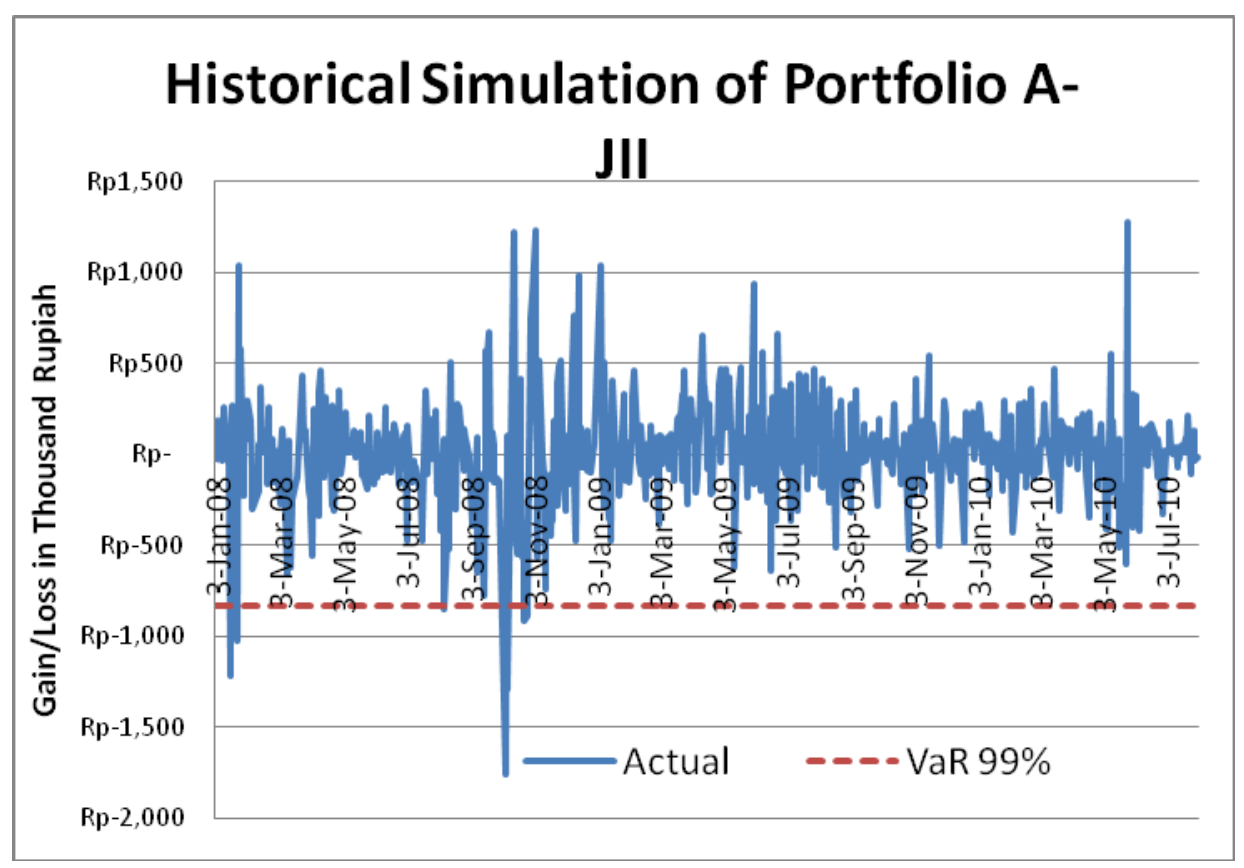

Figure 3. Historical Simulation Portfolio A (99\% confidence level). 
Figure 3 shows the result of historical simulation in Portfolio A-JII on actual daily gains and losses using VaR 99\%. The flat red line was daily maximum loss estimation using historical VaR. The 99\% confidence level VaR was calculated as the first percentile of the Portfolio A-JII for the period of 1 January 2008 to 2 August 2010.

The confidence level of 99\% indicates that for 99 out of 100 trading days, the amount in Portfolio A will increase or decrease, but the decrease will be not more than $\mathrm{Rp} 838,000$. The maximum actual loss is $\mathrm{Rp} 1.151 .000$ in the month of October 2008, due to Subprime Crisis.

Using VaR 99\%, there is possibility in 9 days out of 900 trading days that the actual losses will exceed $\mathrm{Rp}$ 838,000. The same decision making should be made in these days, to sell the portfolio A if the loss reaches Rp 838,000 .

\section{Portfolio B}

The result of the historical simulation from Portfolio B is as follows :

$\begin{array}{lll} & \text { IDR 8,550,000 } \\ \text { VaR 95\% } & \text { Rp -289,645.62 } & \text { 1 Jan 2008-2 Aug 2010 } \\ \text { VaR 99\% } & \text { Rp -505,397.18 } & \text { 1 Jan 2008-2 Aug 2010 }\end{array}$

The maximum loss of Portfolio $B$ with the initial investment of Rp 8,550.000 will be Rp 289.645 and Rp 505.397 with level of confidence 95\% and 99\% respectively. 


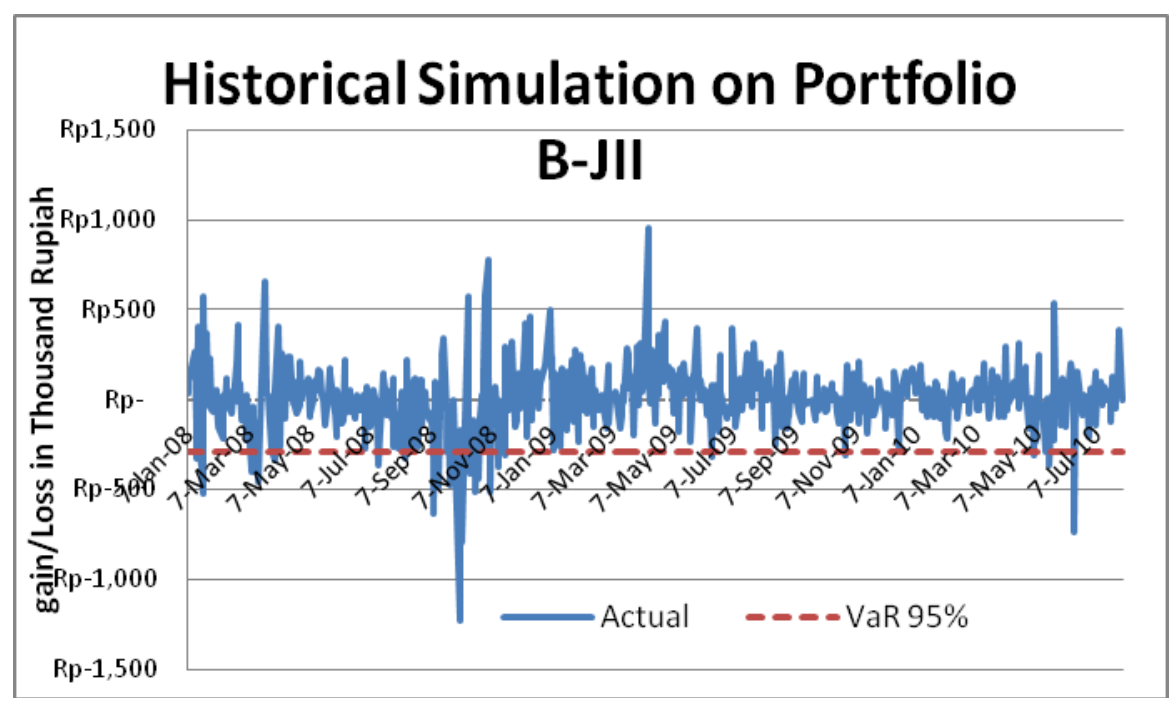

Figure 4. Historical Value-at-Risk (95\% confidence level) for Portfolio B.

Figure 4 shows the result of historical simulation in Portfolio B-JII on actual daily gains and losses using $\mathrm{VaR}$ at $95 \%$. The flat red line was daily maximum loss estimation from historical VaR. The 95\% confidence level VaR was calculated as the fifth percentile of the Portfolio B for the period of 1 January 2008 to 2 August 2010.

The confidence level of 95\% indicates that for 95 out of 100 trading days, the amount in Portfolio B will increase or decrease, but the decrease will be not more than Rp 289,000. The maximum actual loss is Rp 386,220 in the month of October 2008.

Using historical simulation VaR 95\%, there are 45 days out of 900 trading days that the actual losses will exceed Rp 289,000. The portfolio B holds lesser amount of losses comparing to Portfolio A. However, once the value in portfolio B reaches Rp 289,000 the investor should make a decision to cut loss. 


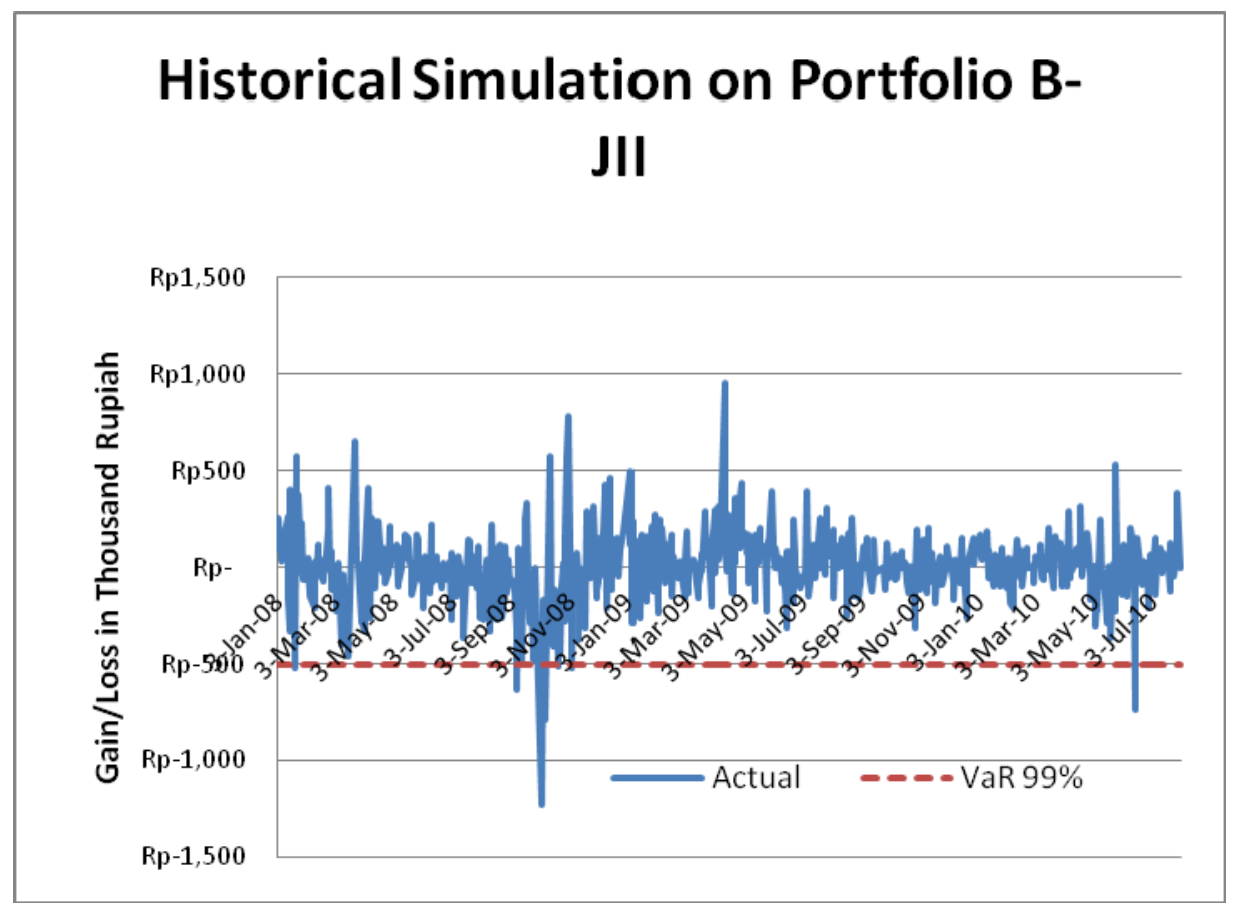

Figure 5. Historical Value-at-Risk (99\% confidence level) for Portfolio B.

Figure 5 shows the result of historical simulation in Portfolio B-JII on actual daily gains and losses using VaR 99\%. The flat red line was daily maximum loss estimation using historical VaR. The $99 \%$ confidence level VaR was calculated as the first percentile of the Portfolio B-JII for the period of 1 January 2008 to 2 August 2010.

The confidence level of 99\% indicates that for 99 out of 100 trading days, the amount in Portfolio B will increase or decrease, but the decrease will be not more than Rp 505,397. The maximum actual loss is Rp 595,000 and happens in October 2008.

Using VaR 99\%, there is possibility in 9 days out of 900 trading days that the actual losses will exceed Rp 505,397. To prevent the further loss, the selling decision should be made once the value decrease to $\mathrm{Rp} 505,397$. 


\section{Portfolio C}

The result of the historical simulation from Portfolio $\mathrm{C}$ is as follows :

\begin{tabular}{lll} 
& \multicolumn{3}{c}{ IDR 5,700,000 } \\
VaR 95\% & Rp -168,583.29 & 1 Jan 2008-2 Aug 2010 \\
VaR 99\% & Rp -299,153.20 & 1 Jan 2008-2 Aug 2010
\end{tabular}

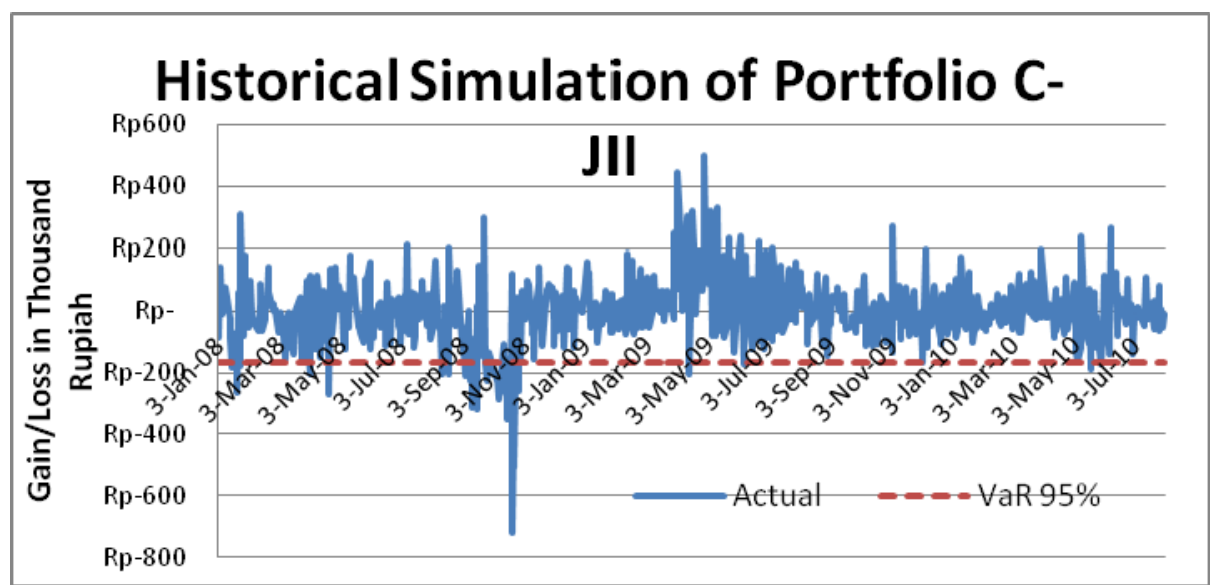

Figure 6. Historical Value-at-Risk (95\% confidence level) for Portfolio C.

The Portfolio C consists of companies that appeared at least three times in the Jakarta Islamic Index. The total companies in Portfolio C are six.

Figure 6 shows the result of historical simulation in Portfolio C-JII on actual daily gains and losses using $\mathrm{VaR}$ at $95 \%$. The flat red line was daily maximum loss estimation from historical VaR, Rp 168,583. The 95\% confidence level VaR was calculated as the fifth percentile of the Portfolio A for the period of 1 January 2008 to 2 August 2010.

The confidence level of 95\% indicates that for 95 out of 100 trading days, the amount in Portfolio $\mathrm{C}$ will increase or decrease, but the decrease will be not more than Rp 168,583. The maximum actual loss is Rp 259,000 in the month of October 2008.

Using historical simulation VaR 95\%, there are 45 days out of 900 trading days that the actual losses will exceed Rp 168,583. Since the maximum 
loss is Rp 259,000, the investor could decide to hold the loss and expect the amount in Portfolio $\mathrm{C}$ will be better in the future.

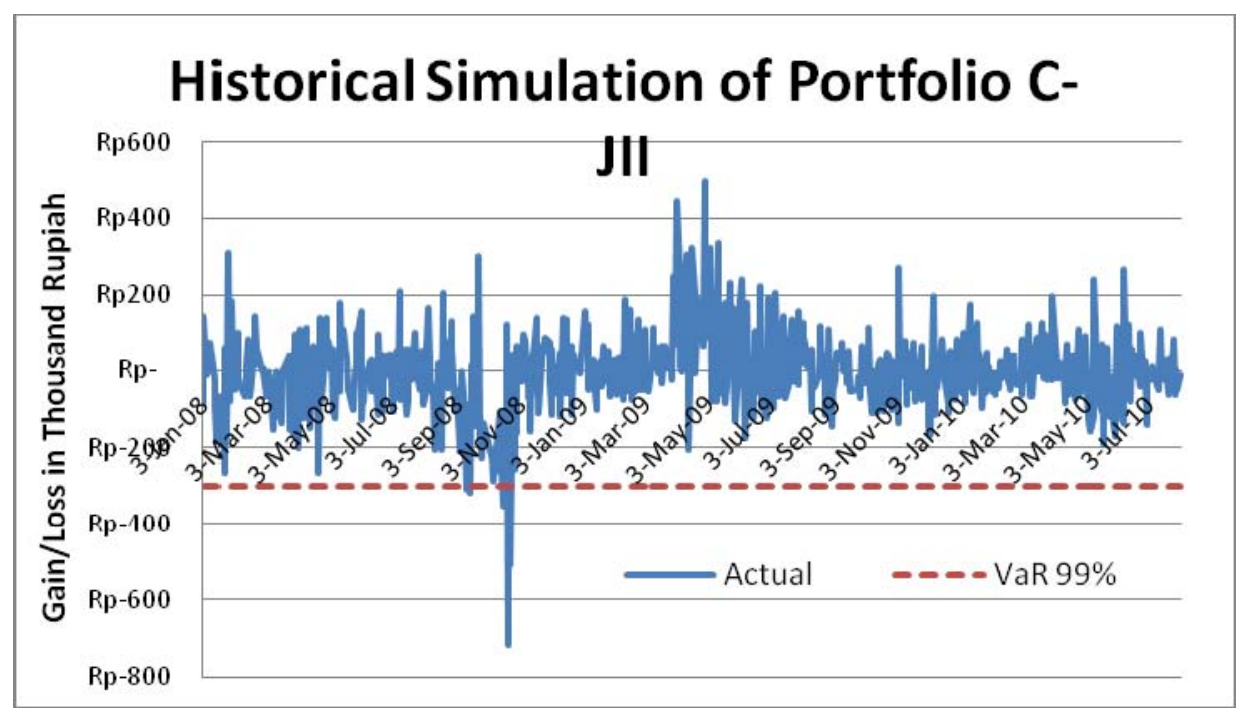

Figure 7. Historical Value-at-Risk (99\% confidence level) for Portfolio C.

Figure 7 shows the result of historical simulation in Portfolio C-JII on actual daily gains and losses using $\mathrm{VaR}$ at $99 \%$. The flat red line was daily maximum loss estimation from historical VaR, Rp 299,153. The 99\% confidence level $\mathrm{VaR}$ was calculated as the first percentile of the Portfolio C for the period of 1 January 2008 to 2 August 2010.

The confidence level of 99\% indicates that for 99 out of 100 trading days, the amount in Portfolio $\mathrm{C}$ will be up and down. The maximum actual loss is $\mathrm{Rp} 368,934$ in the month of October 2008.

Using VaR 99\%, the investor could have the indication of possibility 9 days out of 900 trading days that the actual losses will exceed Rp 299,153. The confidence level 99\% gives higher amount of loss comparing to 95\%. In this case the investor that holds Portfolio $C$ could decide to sell if the loss closes to Rp 299,000. 


\section{Portfolio D}

The result of the historical simulation from Portfolio D is as follows :

IDR 3,800,000

VaR 95\% Rp-130,870.11 1 Jan 2008-2 Aug 2010

VaR 99\% Rp -228,319.31 1 Jan 2008-2 Aug 2010

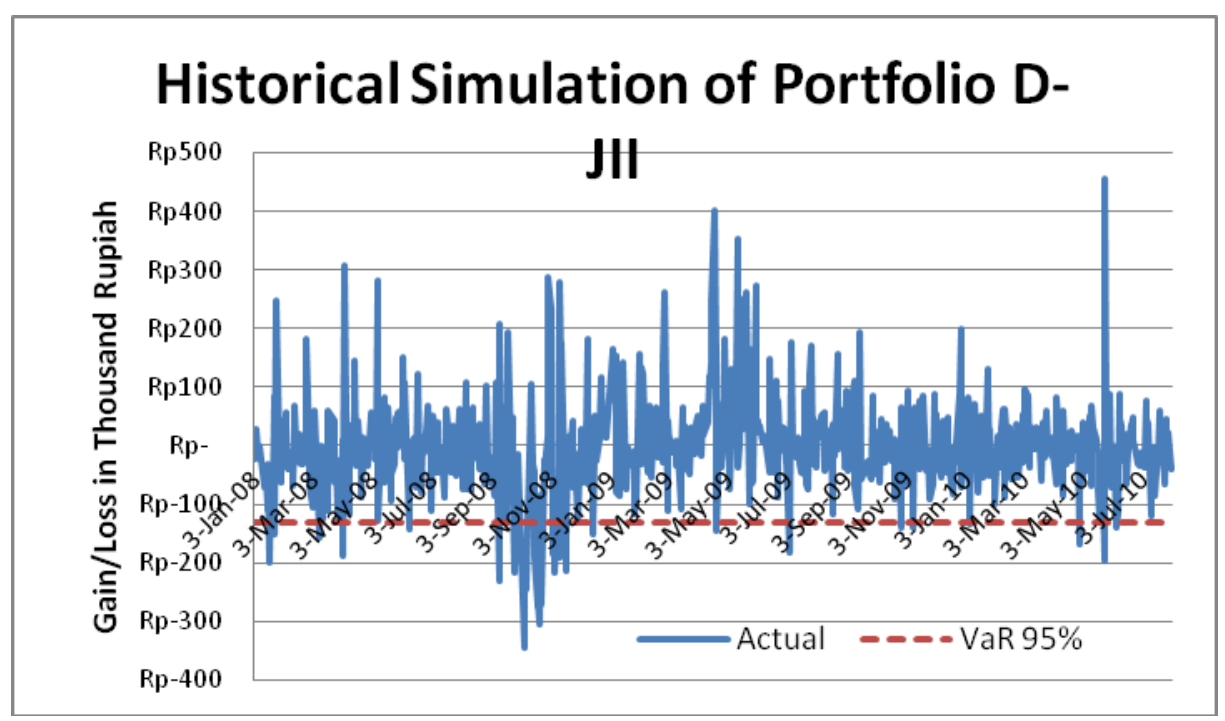

Figure 8. Historical Value-at-Risk (95\% confidence level) for Portfolio D.

In our research design, portfolio $\mathrm{D}$ is the companies that least appeared in Jakarta Islamic Index. The total companies in portfolio D are five.

Figure 8 shows the result of historical simulation in Portfolio D-JII on actual daily gains and losses using $\mathrm{VaR}$ at 95\%. The flat red line was daily maximum loss estimation from historical VaR, Rp 130,870. The 95\% confidence level VaR was calculated as the fifth percentile of the Portfolio A for the period of 1 January 2008 to 2 August 2010.

The confidence level of 95\% indicates that for 95 out of 100 trading days, the maximum loss in Portfolio $\mathrm{D}$ will be $\mathrm{Rp} 130,132$. However, the maximum actual loss is Rp 194,132, and the same with other four portfolio, this loss is due to Subprime Mortgage Crisis. 


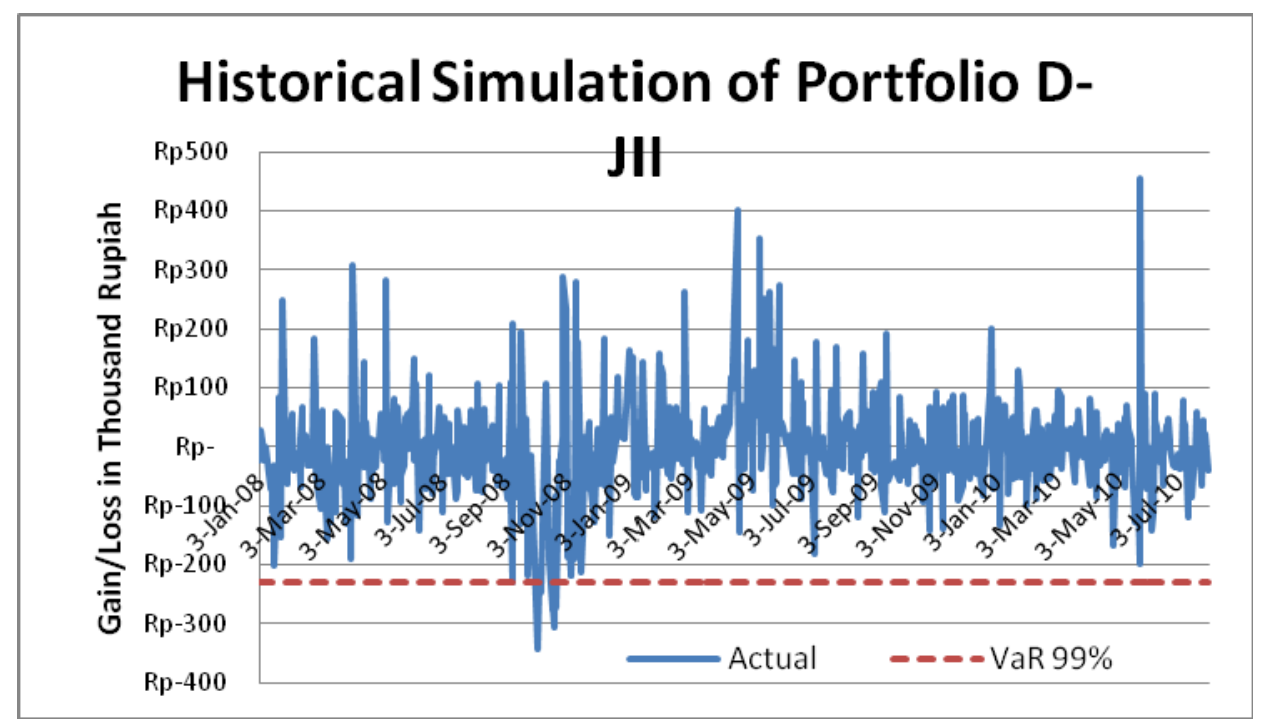

Figure 9. Historical Value-at-Risk (99\% confidence level) for Portfolio D.

Figure 9 shows the result of historical simulation in Portfolio D-JII on actual daily gains and losses using $\mathrm{VaR}$ at $99 \%$. The flat red line was daily maximum loss estimation from historical VaR, Rp 228,319. The 99\% confidence level VaR was calculated as the first percentile of the Portfolio D for the period of 1 January 2008 to 2 August 2010.

The confidence level of 99\% indicates that for 99 out of 100 trading days, the amount in Portfolio D will be up and down. However, the maximum actual loss is Rp 275,235, following the Subprime Mortgage in the month of October 2008.

Using VaR 99\%, the investor could have the indication of possibility 9 days out of 900 trading days that the actual losses will exceed Rp 228,319. The confidence level 99\% gives higher amount of loss comparing to $95 \%$. In this case the investor that holds Portfolio D could decide to sell if the loss closes to Rp 228,319. 
Table 5. Summary of Historical Simulation on Portfolio A,B,C,D

\begin{tabular}{|l|c|c|c|c|c|}
\hline & & \multicolumn{5}{|c|}{ HOLDING PERIOD } \\
\hline & & 1JAN08-2AUG10 & 1JAN-31DEC08 & 1JAN-31DEC09 & 1JAN-02 AUG10 \\
\hline PORTFOLIO A & $95 \%$ & $\mathrm{Rp}-475,003.24$ & $\mathrm{Rp}-628,673.63$ & $\mathrm{Rp}-312,696.56$ & $\mathrm{Rp}-352,377.84$ \\
\hline & $99 \%$ & $\mathrm{Rp}-837,635.85$ & $\mathrm{Rp}-1,151,219.48$ & $\mathrm{Rp}-517,472.06$ & $\mathrm{Rp}-478,136.19$ \\
\hline PORTFOLIO B & $95 \%$ & $\mathrm{Rp}-289,645.62$ & $\mathrm{Rp}-386,220.69$ & $\mathrm{Rp}-178,943.96$ & $\mathrm{Rp}-211,697.25$ \\
\hline & $99 \%$ & $\mathrm{Rp}-505,397.18$ & $\mathrm{Rp}-595,209.28$ & $\mathrm{Rp}-276,310.59$ & $\mathrm{Rp}-341,873.25$ \\
\hline PORTFOLIO C & $95 \%$ & $\mathrm{Rp}-168,583.29$ & $\mathrm{Rp}-258,894.27$ & $\mathrm{Rp}-110,424.98$ & $\mathrm{Rp}-118,004.87$ \\
\hline & $99 \%$ & $\mathrm{Rp}-299,153.20$ & $\mathrm{Rp}-368,934.66$ & $\mathrm{Rp}-159,699.69$ & $\mathrm{Rp}-166,044.97$ \\
\hline PORTFOLIO D & $95 \%$ & $\mathrm{Rp}-130,870.11$ & $\mathrm{Rp}-194,132.71$ & $\mathrm{Rp}-91,257.04$ & $\mathrm{Rp}-102,678.43$ \\
\hline & $99 \%$ & $\mathrm{Rp}-228,319.31$ & $\mathrm{Rp}-275,235.25$ & $\mathrm{Rp}-140,043.79$ & $\mathrm{Rp}-155,434.46$ \\
\hline
\end{tabular}

Table 5 summarizes the maximum loss on Portfolio A,B,C,D with different holding periods. From the table it is obvious the maximum loss on every portfolios is worse during year 2008. This is because the portfolio on Jakarta Islamic Index also affected with global crisis caused by subprime mortgage. The maximum loss for level of confidence $99 \%$ is bigger than level of confidence $95 \%$.

\section{CONCLUSION}

The paper is an exploratory study of VaR in portfolios of Jakarta Islamic Index. A very volatile portfolio will generate high VaR figure, and this will indicate to investor that current portfolio has a very high probability of making significant losses. Value at Risk has been widely used by many organizations and implemented by Basel committee as well as many central banks of as a way of monitoring and managing market risk and as one of the basis for making investments decisions.

The choice of confidence level will give different results on each portfolio. We include the year 2008 to see the impact of subprime mortgage will increase the value of $\mathrm{VaR}$ on each portfolios. 
The smaller amount of VaR can be found in Portfolio D, which consists of only four companies. The number of the member of portfolio could be affected the VaR as well. The possible explanation for Portfolio D is the samples have low volatility of price. One of the member, ADRO, recently becomes a member on Jakarta Islamic Index on July 16, 2008.

As Rampersad (2010) states, the intuition and concept of the Historical Simulation to calculate VaR are simple. As the implementation of building hypothetical four portfolios from Jakarta Islamic Index, the author could easily calculate the VaR return distribution on period observation, obtain the result of the $95 \%$ and $99 \% \mathrm{VaR}$, and compare to the actual maximum loss.

The turbulent event such as Subprime Mortgage was a good test of the historical simulation due to $\mathrm{VaR}$ estimation that closes to the actual loss of the four portfolios. In terms of disadvantage, $\mathrm{VaR}$ tends to show lower risk estimation than actual, due to quiet period of observation.

The historical simulation of $\mathrm{VaR}$ method presented in this paper can be implemented for investor in Indonesia to calculate the risk in Jakarta Islamic Index. The investor can diversify its high and low risk securities in portfolio using VaR and get the most benefit of diversification.

\section{REFERENCES}

Angelidis Timotheos, Benos Alexandros. (2008). Value-at-Risk for Greek Stocks. Multinational Finance Journal, 12(1/2), 67-104.

Basle Committee on Banking Supervision. (2006). An Internal ModelBased Approach to Market Risk Capital Requirements. Basle: Bank for InternationalSettlements.

Begona Fernandez, Laurent Denis. (2009). Estimation of Value at Risk and Ruin Probability for diffusion Processes with Jumps. Mathematical Finance, 19(2), 281-302. 
Bohdalova Mária. (2007). A comparison of Value-at-Risk methods for measurement of the financial risk. E-Leader, Prague.

Bhattacharyya Malay. (2008). Contemporary Financial Risk Management: The Role of Value at Risk (VAR) Models an Academic Perspective. Reprint No 08304a, Bangalore: Indian Institute of Management,

Cakici Nusret, Turan G. Bali. (2004). Value at Risk and Expected Stock Returns. Financial Analysts Journal.

Campbell, R., R. Huisman, K. Koedijk. (2001). Optimal portfolio selection in a Value-at-Risk framework. Journal of Banking \& Finance, 25, 1789-1804.

Chien-Liang Chiu, Ming-Chih Lee, Jui-Cheng Hung. (2005). Estimation of Value-at-Risk under jump dynamics and asymmetric information. Applied Financial Economics, 15, 1095-1106.

Dutta, et al. (2007). Value at risk, GARCH modeling and the forecasting of hedge fund return volatility. Journal of Derivatives \& Hedge Funds, 13.

Goorbergh, R., \& P. Vlaar. (1999). Value-at-Risk Analysis of Stock Returns Historical Simulation, Variance Techniques or Tail Index Estimation?, smarquant.com

Hondoko, Agus. (2009). Analisis implementasi tiga metode pengukuran Value at Risk (Historis, Variance-Covariance dan simulasi MoneCarlo) pada pergerakan harga saham yang termasuk dalam daftar LQ45.Jakarta: BINUS University library.

Hoyt E. Robert, Powell S. Lawrence, \& Sommer W. David. (2007). Computing Value at Risk: a simulation assignment to illustrate the value of enterprise risk management. Risk Management and Insurance Review, 10(2), 299-307. 
Jorion, P. (2002). Value at Risk. The new Benchmark for Managing Financial Risk. Singapore: McGraw-Hill International Edition.

Karthik Natarajan, Pachamanova Dessislava, Sim Melvyn. (2008). Incorporating Asymmetric Distributional Information in Robust Value-at-Risk Optimization. Management Science, 54(3), 573585, Informs.

Linsmeier J. Thomas , Pearson D. Neil. (2000). Value at Risk. Financial Analysts Journal.

Maher Kooli, Serge Patrick Amvella, Jean-Pierre Gueyie. (2005). Hedge funds in a portfolio context: A mean-modified value at risk framework. Derivatives Use, Trading \& Regulation, 10(4), 373383. Henry Stewart Publications.

Philippe A., F. Delbaen, J.M. Eber, \& D. Heath. (1999). Coherent measures of risk. Math. Finance, 9(3), 203-228.

PRMIA Professional Risk Managers' International Association (2005). The Professional Risk Managers' Handbook: A Comprehensive Current Theory and Best Practices. Volume III, A2 and A3. New York, USA: PRMIA Publications.

Rampersad, Travis. (2012). Simple Value-at-Risk Model for Equity Portfolio. Investment Weekly: Bulletin of First Citizen Investment Services, January 2012. Trinidad and Tobago.

Sanjaya, V. A. (2009). Analisis dan Pengujian Tiga Metode Value-AtRisk pada Portfolio Saham di Indonesia dan Amerika. Jakarta: BINUS University Library. 